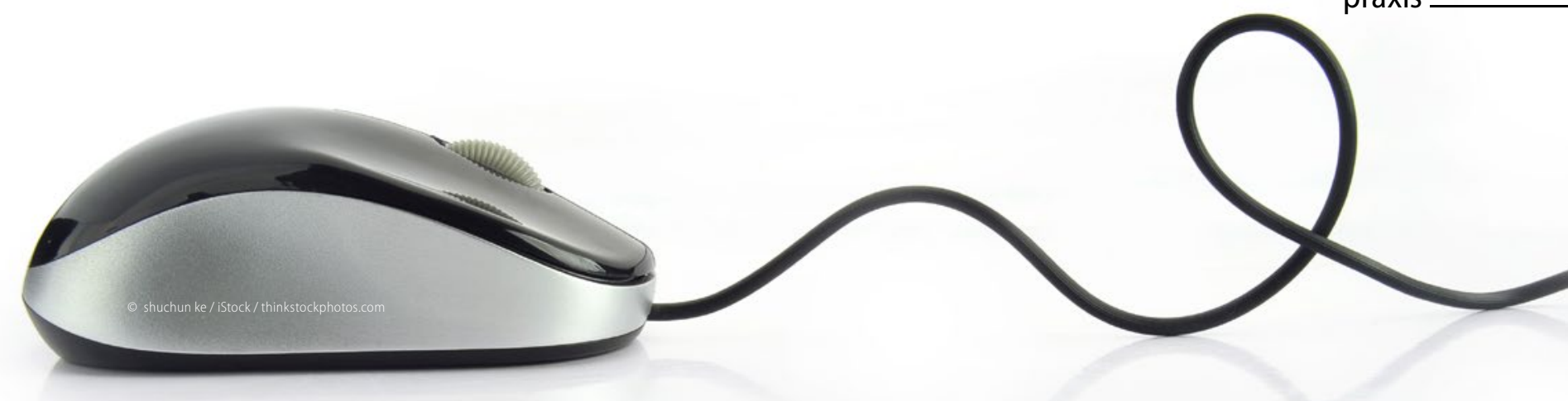

\title{
Gut, besser - PRAXISHANDBUCH print und online
}

Mit Informationen, Tipps und Ratschlägen zu Abrechnungsfragen, betriebswirtschaftlichen und rechtlichen Themen bietet das PRAXISHANDBUCH eine solide Grundlage für die Organisation des freiberuflichen Unternehmens Zahnarztpraxis. Die Bewertung aktueller gesundheitspolitischer Entwicklungen in ihren Auswirkungen auf den Praxisablauf kommt dabei ebenfalls nicht zu kurz.

Im Zeitalter elektronischer Wissensverarbeitung geht auch das PRAXISHANDBUCH moderne Wege. Es gibt jetzt zusätzlich eine internetbasierte Variante des Nachschlagewerks.

Der Inhalt steht aufbereitet im Internet zur Verfügung. Durch eine Menüführung lassen sich alle Kapitel aufrufen und im Netz lesen. Bei Bedarf können die Seiten dann auch ausgedruckt werden.
In der elektronischen Version ist es möglich, immer aktuell zu sein, während wir in der Papierversion durch logistische Vorgaben an den halbjährlichen Ausgabemodus gebunden sind. Außerdem entfällt das Einsortieren der Ergänzungslieferung in der Praxis.

Das elektronische PRAXISHANDBUCH wird als eigenes Produkt vertrieben und kann abonniert werden. Dies gilt auch für die bisherigen Abonnenten der Papierversion. Dabei bitten wir um Mitteilung, ob Sie Ihr Abo ergänzen, umstellen oder erweitern möchten. Ein entsprechendes Formular finden Sie im Internet unter www.fvdz.de.

Abonnenten der bisherigen Papierversion erhalten die WebVersion ohne Einrichtungskosten.

Die Preise entnehmen Sie bitte nachfolgendem Bestellcoupon.

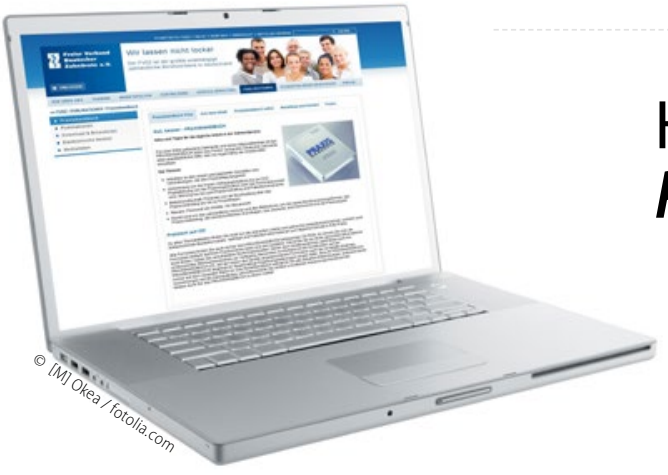

\section{Papierversion}

$\square 45 €$ für FVDZ-Mitglieder

$\square 95 €$ für Nichtmitglieder

$\square$ Ich möchte auch die Ergänzungslieferungen regelmäßig erhalten

$\square 20 €$ für FVDZ-Mitglieder

$\square 27,50 €$ für Nichtmitglieder

\section{Hiermit bestelle ich PRAXISHANDBUCHES zum Einzelpreis von}

\section{Web-Version}

$\square 30 €$ Einrichtung für FVDZ-Mitglieder*

$+36 €$ Jahresabo für FVDZ-Mitglieder

$\square 60 €$ Einrichtung für Nichtmitglieder*

$+48 €$ Jahresabo für Nichtmitglieder

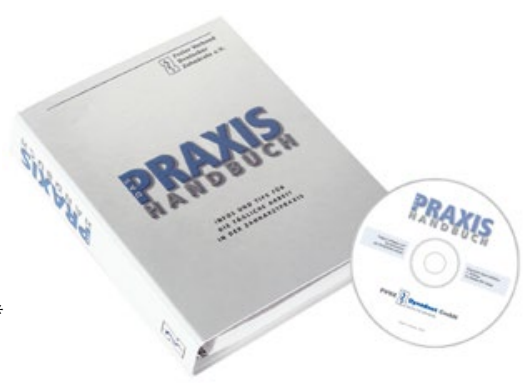

\section{Papierversion + Web-Version}

ggf. Mitgliedsnummer

Name

Straße

PLZ/Ort $\square 60 €$ Basiswerk + Einrichtung für FVDZ-Mitglieder

$+60 €$ Jahresabo + Ergänzungslieferung für FVDZ-Mitglieder

$\square 140 €$ Basiswerk + Einrichtung für Nichtmitglieder

+ $90 €$ Jahresabo + Ergänzungslieferung für Nichtmitglieder 